\title{
Traceable Standards for Electrolytic Conductivity Measurements Required for Pharmaceutical Production
}

\author{
Philipp Arquint*, Hannes Bühler, and Stefan Worbs
}

\begin{abstract}
Certified reference materials for low electrolytic conductivity can now be produced successfully that meet the basic criteria of a high quality technical standard for industrial purposes. The materials are very stable and easy to handle. The values for these high quality references have low uncertainties and are traceable to international standards by an unbroken chain of comparison. These certified reference materials can be used to check the compliance with the requirements for pharmaceutical grades of water. Water for injection (WFI) or highly purified water (HPW) can now be checked reliably against the limiting values set by the European and United States Pharmacopeia using instruments that are calibrated with low level electrolytic standards. The comparability of the results has been demonstrated on occasion of an intercomparison between expert reference laboratories.
\end{abstract}

Keywords: Electrolytic conductivity · Pharmaceuticals · Reference material · Traceability · USP $<645>$

\section{Introduction}

Stable and certified reference materials (CRM) for electrolytic conductivity at low levels are a prerequisite for production facilities of the pharmaceutical industry. Highly purified water (HPW) and water for injection (WFI) have to fulfil a number of chemical and physical criteria including a limit for the electrolytic conductivity, that is now set to $1.1 \mu{\mathrm{S} . \mathrm{cm}^{-1}}\left(20^{\circ} \mathrm{C}\right)$ and 1.3 $\mu \mathrm{S} . \mathrm{cm}^{-1}\left(25^{\circ} \mathrm{C}\right) .{ }^{[1]}$ Water for injection is water purified by distillation or by a purification process that is equivalent or superior to distillation in the removal of chemicals and microorganisms. It is prepared from water complying with the U.S. Environmental Protection Agency National Primary Drinking Water Regulations or with the USP $<29>$ drinking water regulations

${ }^{*}$ Correspondence: Dr. P. Arquint HAMILTON Bonaduz AG

Via Crusch 8

$\mathrm{CH}-7402$ Bonaduz

Tel.: +4181660 6326

Fax: +418166060 70

E-mail: parquint@hamilton.ch of the European Union, Japan, or with the World Health Organization's Guidelines for Drinking Water Quality. It is not permitted to add substances to the purified water. Water for Injection is intended for use in the preparation of parenteral solutions. ${ }^{[2]}$ Organic compounds that do not produce ions when dissolved in water cannot be detected by a conductivity measurement. Total organic carbon is regulated separately. ${ }^{[3]}$ All ionic species dissolved in water will contribute more or less, depending mainly on their mobility and charge to the sum parameter electrolytic conductivity. In very dilute systems the conductivity is almost proportional to the content of dissolved salts.

Absolute pure water has a conductivity of $0.055 \mu \mathrm{S} \cdot \mathrm{cm}^{-1}\left(25^{\circ} \mathrm{C}\right)$ or a resistivity of $18.18 \mathrm{M} \Omega \cdot \mathrm{cm}$ (originating from the self dissociation of the water resulting in $10^{-7}$ $\mathrm{M}$ hydrated protons and $10^{-7} \mathrm{M}$ hydroxide ions at $25^{\circ} \mathrm{C}$. Compared to seawater, which has a conductivity of approximately $0.043 \mathrm{~S} \cdot \mathrm{cm}^{-1}\left(15^{\circ} \mathrm{C}\right), 0.048 \mathrm{~S} \cdot \mathrm{cm}^{-1}\left(20^{\circ} \mathrm{C}\right)$ and $0.053 \mathrm{~S} \cdot \mathrm{cm}^{-1}\left(25^{\circ} \mathrm{C}\right)$, the value for high purity water is about a factor of one million lower.

Apart from limiting values for the conductivity of water a number of further requirements have to be fulfilled by the measurement equipment and the measurement procedure to comply with the prescribed regulation. ${ }^{[1]}$

The liquid reference materials are mainly used to check and calibrate the conductivity measurement instruments. From the known value $\kappa_{\mathrm{r}}$ for the electrolytic conductivity of the reference standard used and the measured electrical resistance $R_{\mathrm{r}}$ at a defined temperature the cell constant $K_{\text {cell }}$ for the system is calculated by a user of the CRM according to Eqn. (1).

$K_{\text {cell }}=\kappa_{r} \cdot R_{r}$

For low level electrolytic conductivity measurements a standard with an electric conductivity of $5 \mu \mathrm{S} \cdot \mathrm{cm}^{-1}\left(25^{\circ} \mathrm{C}\right)$ is appropriate for the calibration. Once the cell constant $K_{\text {cell }}$ is known the electrolytic conductivity $\kappa$ of liquid samples are evaluated by determining the electrical resistance $R$ at a defined temperature ( $c f$. Eqn. (2)).

$\kappa=\frac{\kappa_{\mathrm{r}} \cdot R_{\mathrm{r}}}{R}=\frac{K_{c e l l}}{R}$

If the nominal temperature does not agree with the actual temperature of the test solution the values are corrected by using an empirical polynomial equation that describes the conductivity signal from the measurement equipment and the reference material involved. This introduces further uncertainties for the result. Apart from temperature also the environment in which samples are manipulated is important. As carbon dioxide in air has an amount fraction of about $385 \mu \mathrm{mol} \cdot \mathrm{mol}^{-1}\left(\cong 385 \mathrm{~cm}^{3}\right.$ pure $\mathrm{CO}_{2}$ gas per $\mathrm{m}^{3}$ air) it can influence the measurements and the solutions need to be handled with precautions. Such calibrations have to be performed at regular intervals as the measurement sensor can be altered when real world samples are measured over a prolonged period of time. The surface of the electrode can change by adsorption of substances or the geometry may be slightly changed during operation 
or manipulations of the measurement sensor device. Depending on the expected value for the conductivity of a sample the calibration standards have to be chosen and also the equipment may be adapted.

The following certified standards from HAMILTON cover a very broad range of conductivity: $1.3 \mu \mathrm{S} \cdot \mathrm{cm}^{-1}, 5 \mu \mathrm{S} \cdot \mathrm{cm}^{-1}, 15$ $\mu \mathrm{S} \cdot \mathrm{cm}^{-1}, 100 \mu \mathrm{S} \cdot \mathrm{cm}^{-1}, 147 \mu \mathrm{S} \cdot \mathrm{cm}^{-1}, 1413$ $\mu \mathrm{S} \cdot \mathrm{cm}^{-1}, 12288 \mu \mathrm{S} \cdot \mathrm{cm}^{-1}$ (all nominal values for $25^{\circ} \mathrm{C}$ ) and are suitable for many users. The relative expanded uncertainty is $\pm 1 \%(k=2)$. The low electrolytic conductivity calibration solutions $0.5 \mu \mathrm{S} \cdot \mathrm{cm}^{-1}$ to $146 \mu \mathrm{S} \cdot \mathrm{cm}^{-1}$ have been described in a patent. ${ }^{[4]}$ Sucrose-based low conductivity standards were reported by Light et al..$^{[5]}$ The well-know empirical Walden rule, which states that the product of electrolytic conductivity and dynamic viscosity is a constant irrespective of the solvent was applied in these cases. ${ }^{[6]}$

\section{Certified Properties of Conductivity Standards and Traceability Chain}

Stability studies performed for standards developed at HAMILTON show that even the low level standard of $5 \mu \mathrm{S} \cdot \mathrm{cm}^{-1}$ keeps its characteristic value for three years to better than the tolerance value set at one percent (Fig. 1).

The long shelf life could be achieved by keeping the liquid standard in tightly closed borosilicate bottles with polypropylene screw caps and a defined liquid composition with a lower dielectric constant than pure water, that are special organic solvents which reduce the mobility of ions by their increased dynamic viscosity. Hence higher salt concentrations are feasible in low conductivity standards thus reducing the influence of contaminations. Solvents with high dielectric constant favour the production of ions as the electrostatic forces between ions are reduced. The temperature dependence of the conductivity is then mainly influenced by the temperature dependence of the viscosity. The polymer caps have a broad sealing surface in touch with the bottle lip. The caps prevent the migration of gaseous carbon dioxide through the cap material and the carbon dioxide influx at the sealing surface. The leaching of the glass type by the liquid standard is much reduced or absent if the dielectric constant is low. The reaction of water with trace carbon dioxide in the standard material with lowered dielectric constant produces less ions that increase the conductivity compared to the situation in pure water. ${ }^{[7]}$ It follows that the composition of the liquid standard is important to achieve the long shelf life. ${ }^{[8]}$ Long-term stability data of electrolytic

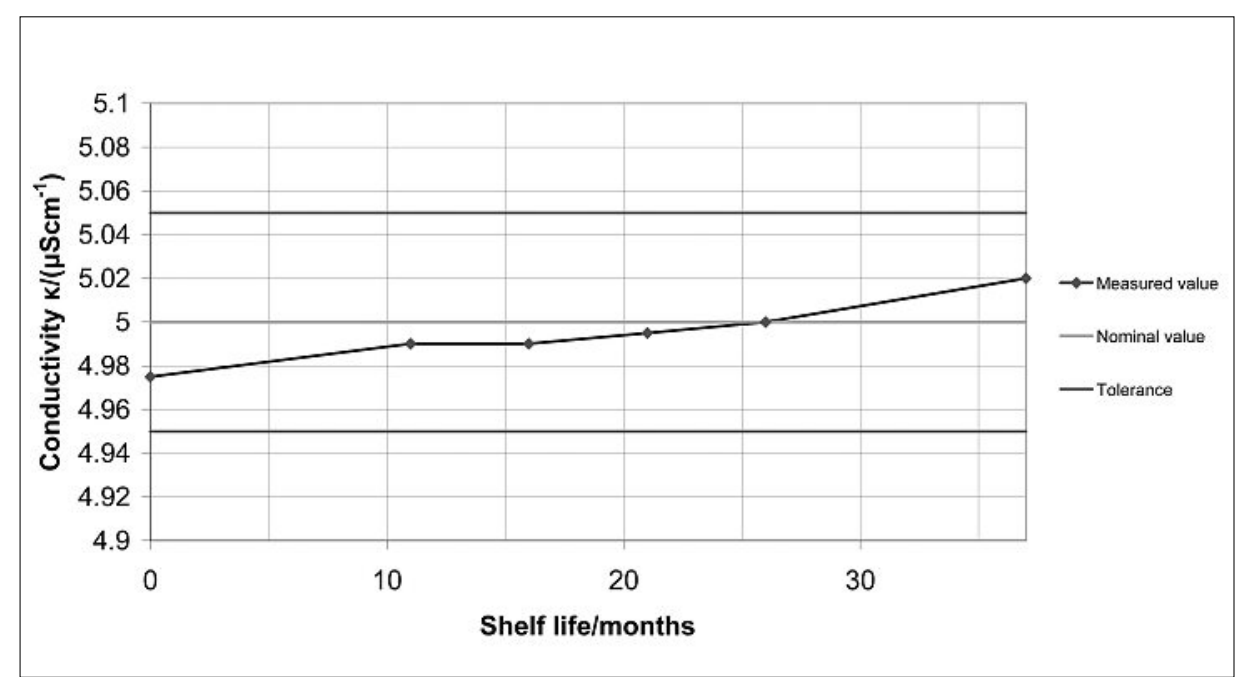

Fig. 1. Stable values for the HAMILTON $5 \mu \mathrm{S}^{\circ} \mathrm{cm}^{-1}$ standard are achieved and are guaranteed for 36 months. The actual value is within the tolerance gap of better than $\pm 1 \%\left(4.95 \mu \mathrm{S}^{\cdot} \mathrm{cm}^{-1} \leq \kappa_{\mathrm{r}} \leq\right.$ $\left.5.05 \mu \mathrm{S} \cdot \mathrm{cm}^{-1}\right)$. The certified value $\kappa_{r}=5 \mu \mathrm{S} \cdot \mathrm{cm}^{-1}$ was confirmed by the German National Metrology Institute (Physikalisch-Technische Bundesanstalt PTB, Braunschweig, Germany).

reference standards are hardly available. Some well-known standards contain about $30 \%$ 2-propanol. The mobility is therefore moderately reduced and very low salt contents make these standards susceptible to contaminations. For such material it is very challenging to achieve and maintain low uncertainties. For the low aqueous electrolytic conductivity NIST SRM 3198, with a certified value of $5.31 \mu \mathrm{S} \cdot \mathrm{cm}^{-1} \pm 0.45$ $\mu \mathrm{S} \cdot \mathrm{cm}^{-1}(k=1.96)\left(\right.$ at $\left.25^{\circ} \mathrm{C}\right)$, the specified shelf life is 10 months (27.1.2009 until 27.11.2009) according to the information on the certificate. The shelf life for NIST SRM 3190 with a certified value of 25.07 $\mu \mathrm{S} \cdot \mathrm{cm}^{-1} \pm 0.22 \mu \mathrm{S} \cdot \mathrm{cm}^{-1}(k=1.96)$ (at 25 ${ }^{\circ} \mathrm{C}$ ) is specified to be almost 11 months (31.3.2009 until 17.2.2010). For standards with higher conductivity values the period for expiration is larger. For these higher electrolytic conductivities IUPAC recommends values for potassium chloride solutions with the corresponding uncertainties and the temperature correction equations. [9] Stability can only be achieved if leaching is reduced, water evaporation through the cap out of the bottle and access of gaseous carbon dioxide into the liquid from the air are minimised. Leaching is the term for a number of complex surface erosion reactions that are influenced by the composition of the liquid and the composition of the solid in contact with each other. The ions originating from the solid glass matrix (e.g. $\mathrm{Na}^{+}$or $\mathrm{B}(\mathrm{OH})_{4}^{-}$) are slowly produced by the reaction with water as the free energy of acquation for ions is negative and driven mainly by the entropy term. The physical processes of slowly changing the conductivity by water diffusing out (concentration effect) and carbon dioxide diffusing in (chemical effect) through the cap polymer material over a prolonged period are dependent mainly on the cap material and cap tightness as well as temperature and partial pressure of carbon dioxide. The subsequent dissolution process of carbon dioxide is followed by the chemical reactions producing ions $\left(\mathrm{H}^{+}\right.$and $\mathrm{HCO}_{3}^{-}$in water) that will slightly and slowly increase the conductivity. All processes involved increase the electrolytic conductivity slowly over time. The standards produced at HAMILTON are checked in two stages: Firstly verification and measurement at HAMILTON and secondly the verification and certification by the Danish Institute of Fundamental Metrology (DFM). The very experienced scientists at DFM used their specialised equipment composed of the primary conductivity measurement cell, the conductivity measurement instrument and temperature sensors to perform the comparison. DFM is one of the leading national metrology laboratory (NMI) that has shown its competence in the field over a long period of time and has the necessary calibration and measurement capability (CMC) according to the requirements of the BIPM.[10] The primary measurement cell of DFM ultimately serves as the powerful tool in the traceability to the SI. Traceability to the international system of units (SI) is therefore realised for the HAMILTON certified reference materials. ${ }^{[11]}$ DFM, NIST and OMH (Országo Mérésügyi Hivatal, Hungarian National Metrology Institute, Budapest) compared their results of measurements using potassium chloride solutions with nominal conductivities of $100 \mu \mathrm{S} \cdot \mathrm{cm}^{-1}, 1 \mathrm{mS} \cdot \mathrm{cm}^{-1}$, and $10 \mathrm{mS} \cdot \mathrm{cm}^{-1}$ at $25^{\circ} \mathrm{C} \cdot{ }^{[12]}$ The results agreed well within measurement uncertainties. In this international comparison DFM considered uncertainties originating mainly from four sources: cell constant, conductivity measurements, resistance measurements including temperature influence and 


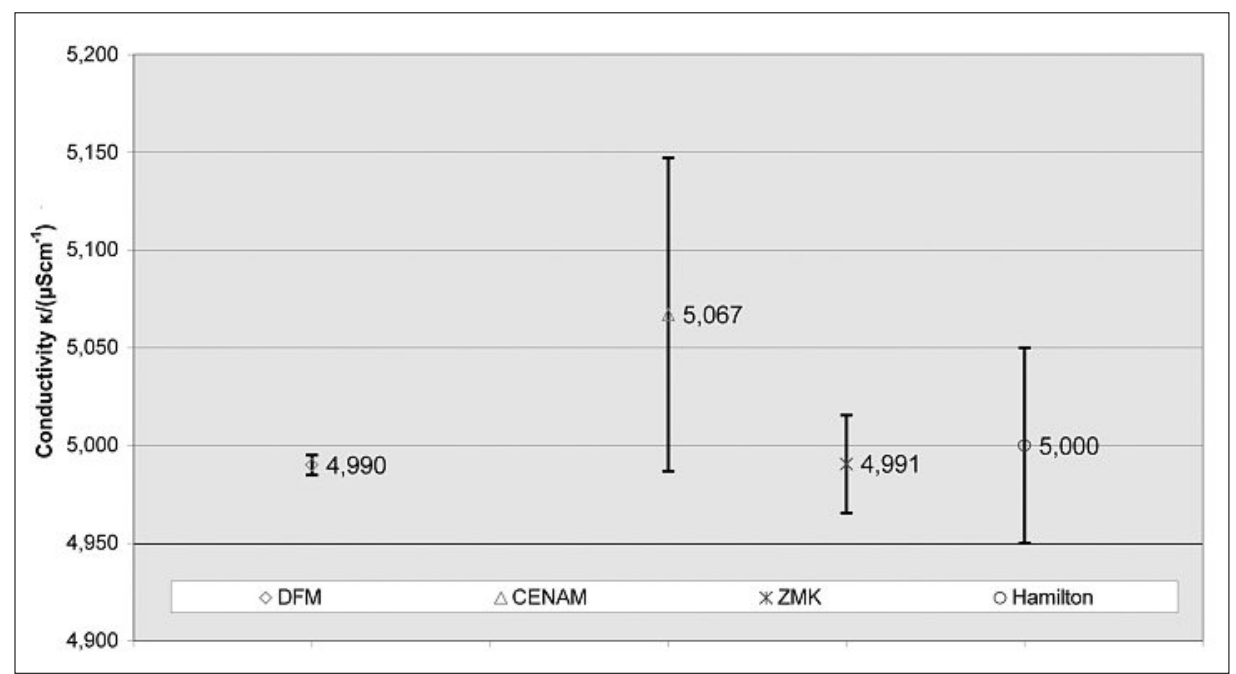

Fig. 2. Intercomparison of the HAMILTON electrolytic conductivity standard with nominal 5 $\mu \mathrm{S} \cdot \mathrm{cm}^{-1}$ measured at $25^{\circ} \mathrm{C}$. Mean value each measured in three different bottles for each participant (NMIs, calibration laboratory, and CRM producer, i.e. DFM, CENAM, ZMK-Analytik, HAMILTON) from the same lot. The expanded uncertainty is indicated by the bars $(k=2)$.

influence from carbon dioxide. In an intercomparison between the Mexican National Metrology Institute (CENAM), DFM and the very experienced calibration laboratory ZMK-Analytik (Zentrum für Messen und Kalibrieren, Bitterfeld-Wolfen, Germany) the comparability of measurement was shown for the low level $5 \mu \mathrm{S} \cdot \mathrm{cm}^{-1}$ conductivity standard (Fig. 2.). [13]

The measurements at HAMILTON were performed by using a specially calibrated measurement system. It was calibrated with five different standards:[14,15]

i) Ultra purified water (UPW) at three fixed temperature levels: $15^{\circ} \mathrm{C}, 25^{\circ} \mathrm{C}, 40$ ${ }^{\circ} \mathrm{C}: \mu \mathrm{S} \cdot \mathrm{cm}^{-1}$ (at $15{ }^{\circ} \mathrm{C}$ ), $0.055 \mu \mathrm{S} \cdot \mathrm{cm}^{-1}$ (at $25^{\circ} \mathrm{C}$ ), $0.113 \mu \mathrm{S} \cdot \mathrm{cm}^{-1}$ (at $40{ }^{\circ} \mathrm{C}$ );

ii) Two potassium chloride solutions $(0.01 \mathrm{M}$ and $0.001 \mathrm{M})$ according to ASTM. ${ }^{[16]} 146.93 \mu \mathrm{S} \cdot \mathrm{cm}^{-1}$ (at $25{ }^{\circ} \mathrm{C}$ ), $1408.8 \mu \mathrm{S} \cdot \mathrm{cm}^{-1}$ (at $25^{\circ} \mathrm{C}$ ).

The values for primary standard reference materials for electrolytic conductivity given by Shreiner and Pratt (1408.23 $\mu \mathrm{S} \cdot \mathrm{cm}^{-1}$ (at $25^{\circ} \mathrm{C}$ )) are based on the molality scale and are not identical with the values listed in the ASTM standard (1408.8 $\mu \mathrm{S} \cdot \mathrm{cm}^{-1}$ (at $\left.25^{\circ} \mathrm{C}\right)$ ) based on the molarity scale and may be explained as well by the different way solid potassium chloride was dried. ${ }^{[17]}$ Water occluded in imperfect potassium chloride crystals will not be fully released if dried only at $150{ }^{\circ} \mathrm{C}$ for two hours, for this purpose four hours at 500 ${ }^{\circ} \mathrm{C}$ are needed.

As temperature is one of the key influence parameters for electrolytic conductivity the control and measurement of the temperature is of great importance. Generally the electrolytic conductivity increases with increasing temperature and has a temperature sensitivity of about plus two percent per degree Celsius for potassium chloride dissolved in water at $25^{\circ} \mathrm{C}$.
The temperature sensor used was a class A platinum resistance device according to the norm IEC 751.[18] The measurement instrument device and the cables connecting the conductivity cell have their own resistances or impedances. These contributions are corrected by using certified precision resistances supplied by NIST (National Institute of Standards and Technology, U.S. federal agency in the U.S. Department of Commerce).

Each batch of HAMILTON standard is checked at DFM and the measured value is supplied with the corresponding certificate. The conductivity value measured by the producer serves as verification. The certificate issued by DFM informs the customer according to the ISO Guide 31 about the value of the conductivity of the liquid standard and its expanded measurement uncertainty including further important information connected to the certified reference material.[19] The most relevant information is also displayed on the labels of the bottles.

\section{Conclusions}

The production of conductivity standards at the very low level range has been achieved. These standards are most suitable for the pharmaceutical production industry where a critical level of conductivity of the water has not to be exceeded. It was proved that these delicate standards hold their certified values within the shelf life of three years. The values for the liquids of all production batches of the standards are checked by a national metrology institute that is able to compete with its measurement capability at the highest level of measurement hierarchy. The control mechanisms used by HAMILTON in the production of low conductivity reference materials have been shown to be effective so that liquid materials can even be used in international intercomparisons by NMIs.

\section{Acknowledgements}

We are thankful to the guest editor of this issue Dr. Samuel Wunderli (METAS) for giving scientific advice and support to this contribution.

Received: July 28, 2009

[1] United States Pharmacopeia 31, USP, National Formulary 26, Chapter <645> 'Water conductivity', Rockville, 2008.

[2] United States Pharmacopeia 31, USP, Chapter $<1231>$ 'Water for pharmaceutical purposes', Rockville, 2008.

[3] United States Pharmacopeia 31, USP, Chapter $<643>$ 'Total organic carbon', Rockville, 2008.

[4] H. Bühler, EP 1659397 B1, 2004, 'Kalibrationslösung für die Konduktometrie'.

[5] T. S. Light, E. S. Atwood, J. Driscoll, Anal. Chem. 1993, 65, 181.

[6] P. Walden, H. Ulich, G. Busch, Z. Physik. Chem 1926, 123, 429; P. Walden, E. I. Birr, Z. Physik. Chem. 1931, 153, 1.

[7] R. H. Shreiner, J. Res. Natl. Inst. Stand. Technol. 2002, 107, 393.

[8] Y. C. Wu, P. A. Berezansky, J. Res. Natl. Inst. Stand. Technol. 1995, 100, 521 .

[9] K. W. Pratt, W. F. Koch, Y. C. Wu, P. A Berezansky, Pure Appl. Chem. 2001, 73, 1783.

[10] Bureau International des Poids et Mesures, 'BIPM Measurement capability database CMCs', http://kcdb.bipm.org/appendixC/, (cf. electrical conductivities, liquids).

[11] H. D. Jensen, P. Hyllested, 'DFM measurements on Hamilton WO9690548', Danish Institute of Fundamental Metrology, Lyngby, 2006.

[12] R. H. Shreiner, J. Fuko, H. D. Jensen, M. Wandel, J. Sørensen, Metrologia 2001, 38, 549.

[13] Final report for the intercomparison on electrolytic conductivity $2007\left(5 \mu \mathrm{S}^{\cdot} \mathrm{cm}^{-1}\right), 200810-16$, p.8, ZMK-Analytik, Zentrum für Messen und Kalibrieren, Bitterfeld-Wolfen Germany.

[14] T. S. Light, Anal. Chem. 1984, 56, 1138.

[15] T. S. Light, S. Licht, A. C. Bevilacqua, K. R. Morash, Electrochemical and Solid-State Letters, 2005, 8, E16-E19.

[16] ASTM D1125: 2009, 'Standard Test Methods for Electrical Conductivity and Resistivity of Water'.

[17] R. H. Shreiner, K. W. Pratt, NIST Special Publication 260-142, 2004, 'Standard reference materials: Primary Standards and Standard Reference Materials for Electrolytic Conductivity'.

[18] DIN EN 60751: 1996, translated IEC 751, 'Industrielle Platin-Widerstandsthermometer und Platin-Messwiderstände'.

[19] ISO Guide 31: 2000, 'Certified reference materials - Contents of certificates and labels'. 